\title{
Caracterização do melão tipo Galia durante a maturação.
}

\author{
Josivan B. Menezes ${ }^{1}$; Adimilson B. Chitarra ${ }^{2}$; M $^{\mathrm{a}}$. Isabel F.Chitarra ${ }^{2}$; Urquisa O. Bicalho. ${ }^{2}$ \\ ${ }^{1}$ ESAM - Núcleo de Estudos em Pós-colheita - QTC, C. Postal 137, 59625-900 Mossoró-RN; \\ ${ }^{2}$ UFLA - DCA C. Postal 037, 37200-000 Lavras - MG.
}

RESUMO

Com o objetivo de avaliar a qualidade do melão tipo Galia (Cucumis melo L. var. reticulatus), híbrido Nun 1380, durante a maturação, montou-se um experimento em delineamento inteiramente casualizado, composto de cinco tratamentos e oito repetições de um fruto cada. Os frutos foram colhidos em cinco estádios de maturação: I, II, III, IV e V e as avaliações foram feitas 24 horas após a colheita. Houve tendência à redução na firmeza da polpa durante a maturação, entretanto, não se observou diferença significativa $(\mathrm{p}<0,05)$ entre os níveis de pectina solúvel e total. O estádio de maturação I apresentou os valores mais baixos de $\mathrm{pH}$, sólidos solúveis, açúcares totais e vitamina $\mathrm{C}$ e os valores mais elevados de acidez total titulável e clorofila total. O estádio de maturação I apresentou o teor mais elevado de açúcares redutores $(2,92 \%)$ e o estádio $\mathrm{V}$ revelou o teor mais baixo $(1,67 \%)$. A redução no teor de açúcares redutores foi concomitante à elevação na concentração de sacarose. O estádio de maturação II apresentou o teor mínimo de sólidos solúveis - SS exigido pelo mercado importador (SS superior a 9\%) e resistência mecânica ao manuseio pós-colheita (firmeza da polpa superior a $50 \mathrm{~N}$ ), sendo o mais indicado para a colheita.

Palavras-chave: Cucumis melo L., estádio de maturação.

\begin{abstract}
Characterization of 'Galia' melon during maturation.

The purpose of this study was to evaluate the quality of 'Galia' melon during maturation (Cucumis melo, L. var. reticulatus), hybrid Nun 1380. The experiment was carried out in a completely randomized design with five treatments and eight replicates each of one fruit. The fruits were harvested at five maturation stages: I, II, III, IV and V, and evaluations made $24 \mathrm{~h}$ after harvesting. Firmness of melon fruits decreased during maturation; however, no significant statistical difference $(\mathrm{p}<0.05)$ was noticed in total and soluble pectin. The maturation stage I showed the lowest values for $\mathrm{pH}$, soluble solids content, total sugars and vitamin $\mathrm{C}$, and the highest values of titratable acidity and total chlorophyll. The maturation stage I showed the highest value of reducing sugar $(2.92 \%)$ while the maturation stage $\mathrm{V}$ showed the lowest (1.67\%). Accumulation of sucrose was concomitant with decreasing concentration of reducing sugar. The data obtained in this study on firmness and soluble solid content indicated that the maturation stage II was the optimun for harvesting 'Galia' melons, hybrid Nun 1380. At this stage the soluble solid content reached more than $9 \%$, which is the minimum standard established for the import market, and the fruits had resistance to postharvest handling due to their firmness higher than $50 \mathrm{~N}$.
\end{abstract}

Keywords: Cucumis melo $L$. maturation stage.

\section{(Aceito para publicação em 20 de julho de 1998)}

$\mathrm{O}$ interesse pela cultura do melão no Rio Grande do Norte tem aumentado nos últimos anos devido à crescente exportação e às condições climáticas ótimas ao seu desenvolvimento (intensidade e duração de luminosidade, temperatura alta e precipitações baixas). Entretanto, o desenvolvimento de tecnologias para o controle de qualidade e conservação pós-colheita não têm acompanhado o ritmo da produção (Souza et al., 1994).

Nos últimos anos, tem-se introduzido na região diversas cultivares do grupo reticulatus, destacando-se o melão 'Galia' com sementes oriundas, principalmente, de Israel, Espanha, Holanda e Grécia. Entretanto, a comercialização tem sido prejudicada pela alta perecibilidade, com vida útil pós-colheita não ultrapassando 14 dias (Lester \& Stein, 1993). O melão 'Galia' é de origem israelense cujos frutos apresentam de 850 a 1900 g. É um tipo varietal com características intermediárias entre o melão tipo Ogen (ou Haogen), polpa verde, doce e bastante aromático e o tipo Honey Dew de polpa verde, doce e sem aroma. A cor da casca é normalmente laranja. Entretanto existem híbridos que não perdem a coloração verde da casca com o amadurecimento completo. A cor da polpa é verde e o aroma e o sabor são semelhantes aos do Ogen (Odet, 1993). A textura da polpa é mediana, com coloração verde-claro na zona externa e branco laranja na interna. $O$ fruto é geralmente redondo e reticulado (cicatrizes nos sentidos longitudinal e transversal formando uma malha), separandose facilmente do pedúnculo quando maduro (Zapata et al., 1989).

Em melão, o termo qualidade tem sido relacionado a diferentes fatores. Uma das características mais estudadas é o teor de sólidos solúveis - SS (Bosland et al. 1979; Fady, 1983; PROTRADE, 1995). O conteúdo de SS, definido como a percentagem de sólidos solúveis no suco extraído da polpa, é um fator tradicionalmente usado para assegurar a qualidade do melão, embora em alguns casos essa característica seja considerada como um falso indicador de qualidade. Segundo Aulenbach \& Worthington (1974) o teor de SS não é um bom indicador de qualidade, especialmente quando está acima de $8 \%$, nas cvs. Mayne Rocky e Gold Star. Estes autores argumentam que aroma, sabor e doçura deveriam ser considerados como características complementares.

Em conseqüência da variação entre talhões, entre frutos da mesma planta e até entre diferentes partes do mesmo fruto (Scott \& MacGillivray, 1940), o conteúdo de SS pode não ser um indicativo 
da grande variabilidade existente no campo, sendo portanto necessárias avaliações adicionais para definir mais adequadamente o estádio de maturação dos frutos. A escolha do estádio ideal de maturação por ocasião da colheita, representa, sem dúvida, uma das principais dificuldades para os produtores de melão (Vaulx \& Aubert, 1977). Este fator torna-se mais importante, quando trabalha-se com material genético desconhecido.

Este trabalho teve como objetivo avaliar a qualidade pós-colheita do melão tipo Galia, híbrido Nun 1380, durante a maturação e determinar o estádio de maturação adequado para colheita.

\section{MATERIAL E MÉTODOS}

Obtenção dos frutos: A área de cultivo para a obtenção dos frutos foi a Fazenda Água Branca I, da FRUNORTE Ltda, no município de Carnaubais-RN. O plantio foi realizado no mês de setembro de 1994, em solo Podzólico vermelho amarelo equivalente eutrófico latossólico de textura arenosa. A análise química do solo revelou: $\mathrm{pH}$ em água 7,6; $\mathrm{pH}$ em $\mathrm{CaCl}_{2}$ 7,0; matéria orgânica 0,9\%; P (resina) $95 \mathrm{mg} / \mathrm{cm}^{3}$; Ca 3,5 meq/

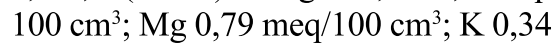
meq/100 cm $; \mathrm{Na} 0,17 \mathrm{meq} / 100 \mathrm{~cm}^{3} \mathrm{e}$ Al $0,00 \mathrm{meq} / 100 \mathrm{~cm}^{3}$.

O espaçamento utilizado foi $2,0 \mathrm{~m}$ entre fileiras e $0,33 \mathrm{~m}$ entre plantas, provendo uma população de 15 mil plantas por hectare. A área total utilizada foi de 0,46 ha (29 linhas de $80 \mathrm{~m}$ ).

A adubação de fundação foi feita com esterco, $15 \mathrm{~m}^{3} /$ ha; superfosfato simples, $1000 \mathrm{~kg} / \mathrm{ha}$; calcário dolomítico, $500 \mathrm{~kg} / \mathrm{ha}$; e magnesita, $100 \mathrm{~kg} / \mathrm{ha}$. A fertirrigação até os 74 dias de plantio (época do segundo corte) foi feita com $\mathrm{N}, 51,5 \mathrm{~kg} / \mathrm{ha} ; \mathrm{P}_{2} \mathrm{O}_{5}, 160 \mathrm{~kg} / \mathrm{ha} ; \mathrm{K}_{2} \mathrm{O}, 268$ $\mathrm{kg} / \mathrm{ha} ; \mathrm{Ca}, 31,35 \mathrm{~kg} / \mathrm{ha}$ e água, $2068 \mathrm{~m}^{3} /$ ha, três vezes ao dia. A adubação foliar foi conduzida com Nutrifolha, $2,73 \mathrm{~kg}$ / ha; mistura de micronutrientes, $4,56 \mathrm{~kg} /$ ha; molibdato de sódio, $0,29 \mathrm{~kg} / \mathrm{ha}$; Nutrimins $\mathrm{CaB}, 20,46 \mathrm{~kg} / \mathrm{ha}$ e sulfato de potássio, 19,6 kg/ha. O controle de ervas daninhas foi realizado com a aplicação de podium $(0,71 /$ ha nove dias após o plantio) e mecânico (17, 34 e 53 dias após o plantio). Durante o experimento não ocorreu precipitação pluviométrica.
A colheita foi feita em duas etapas: primeiro corte (69 dias) e segundo corte aos 74 dias após o plantio. Entretanto, utilizaram-se frutos apenas do primeiro corte para a instalação dos experimentos em laboratório.

Os frutos foram colhidos após 15:00 $\mathrm{h}$ conforme os estádios de maturação: I - frutos de coloração verde-intenso com pedúnculo totalmente preso; II - frutos de cor verde com início de descoloração e pedúnculo totalmente preso; III fruto com pedúnculo em início de abscisão; IV - fruto com pedúnculo totalmente rachado, e V- fruto sem pedúnculo, que representaram os cinco tratamentos.

Imediatamente, após a colheita e seleção (frutos com boas características externas), os melões foram embalados em caixas de mercado externo tipo telescópica ou peça única feita de papelão ondulado de parede dupla, onda BC, com $5 \%$ de área de ventilação. Os frutos foram transportados via terrestre para Natal - RN, distante $230 \mathrm{~km}$ do local de produção, via aérea para Belo horizonte - MG e via terrestre para Lavras - MG, a $220 \mathrm{~km}$ de Belo Horizonte, totalizando 24 horas após a colheita, sempre em condições ambiente. Em Lavras - MG, os frutos foram imediatamente submetidos às avaliações de qualidade.

$\mathrm{O}$ delineamento experimental utilizado foi inteiramente casualizado, com cinco tratamentos e oito repetições, de um fruto por parcela, totalizando $40 \mathrm{fru}-$ tos no experimento.

Avaliações físicas: A firmeza da polpa foi medida como resistência à penetração usando-se penetrômetro (Magness-Taylor modelo $30 \mathrm{~A}$; valor máximo de leitura $30 \mathrm{lb}$ ) com plunger de ponta cônica (diâmetro, $0,83 \mathrm{~cm}$ e comprimento, $0,67 \mathrm{~cm}$ ) em regiões equatoriais (três determinações por fruto) da superfície do fruto desprovido de casca, conforme McCollum et al. (1989).

Preparo das amostras: Após as avaliações físicas separaram-se quatro fatias ( $2 \mathrm{~cm}$ de largura), das quais extraiu-se a polpa comestível. Após homogeneização em liqüidificador, uma porção da polpa foi filtrada, utilizandose parte do suco para as análises imediatas de $\mathrm{pH}$, acidez total titulável e SS e o restante para o doseamento de vitamina
C total e açúcares. O restante da polpa foi cortado em cubos, congelado em nitrogênio líquido, embalado em sacos transparentes de polietileno de baixa densidade $(27,0 \mathrm{~cm} \mathrm{X} 31,0 \mathrm{~cm})$ com fecho hermético e mantido a $-18^{\circ} \mathrm{C}$ para as demais análises.

A casca dos frutos foi congelada em $\mathrm{N}_{2}$ líquido e mantida a $-18^{\circ} \mathrm{C}$ para determinação do teor de clorofila total.

Pectina total e solúvel: A polpa mantida sob $\mathrm{N}_{2}$ líquido foi desintegrada em homogeneizador de tecidos (Tissumizer - Tekmar company, tipo SDT 1880) e as frações pectina total e solúvel foram extraídas pelo método de McCready \& McCoomb (1952) a partir de 5 e 25 g de polpa homogeneizada, respectivamente. Para a hidrólise enzimática de pectina total utilizou-se pectinase (EC.3.2.1.15) de origem fúngica -Aspergillus niger, 1,0U/mg (Merck). Para a determinação da pectina total e da solúvel utilizou-se, após a extração da pectina, diluições 1:20 e 1:4 (v:v), em água, respectivamente, e uma alíquota de $0,2 \mathrm{ml}$ do extrato foi utilizada para comparação com as leituras obtidas pela curva padrão, previamente determinada. Para evitar a interferência de açúcares (glicose, frutose, sacarose e celulose) (Kintner \& Van Buren, 1982) durante a determinação da fração pectina solúvel em água, a polpa foi mantida sob agitação em álcool etílico 95\% (1:5; v:v) durante 1 hora antes da filtração.

A análise foi feita por colorimetria através da reação de condensação do mfenilfenol (m-hidroxibifenil - Eastman Kodak Company ou Sigma Company), segundo técnica adaptada de Blumenkrantz \& Asboe-Hansen (1973). Observou-se a perda de coloração pelo cromóforo a partir da superfície do extrato em poucos minutos (cerca de 30 minutos). Para evitar a instabilidade da reação, e conseqüentemente, a obtenção de resultados inconsistentes, as leituras foram feitas entre 15 e 30 minutos após o início de repouso do sistema. As análises foram feitas em ambiente com temperatura média de $25^{\circ} \mathrm{C}$ e umidade relativa inferior a $60 \%$. A leitura foi monitorada em espectrofotômetro (modelo DU 640 B - Beckman Instruments Inc. USA) a $520 \mathrm{~nm}$, operando com o 
sistema "Power Up Diagnostics Window". O aparelho foi calibrado para fornecer leituras médias de dez repetições a intervalos de 0,5 segundo. Os resultados foram expressos em $\mathrm{mg}$ de ácido urônico por $100 \mathrm{~g}$ de polpa.

Acidez total titulável, pH e sólidos solúveis: $\mathrm{O} \mathrm{pH}$ foi registrado em medidor de $\mathrm{pH}$ digital e a acidez total titulável foi obtida por titulação do suco (diluição 1:5) com $\mathrm{NaOH} 0,1 \mathrm{~N}$ e expressa como mg de ácido cítrico por $100 \mathrm{ml}$ de suco, conforme Artés et al. (1993).

Determinou-se o conteúdo de sólidos solúveis totais por leitura em refratômetro digital, (modelo PR - 100, Palette; Atago Co., LTD., Japão) com compensação automática de temperatura. Os sólidos solúveis foram registrados com precisão de 0,1 a $25^{\circ} \mathrm{C}$ (Kramer, 1973).

Açúcares: As análises de açúcares foram feitas 24 horas a partir da extração do suco, mantido em freezer. Os açúcares redutores e não-redutores foram analisados pelo método de Somoghy-Nelson (Southgate, 1991). Partiu-se, inicialmente, de uma alíquota de $3 \mathrm{ml}$ de suco, diluída para $100 \mathrm{ml} \mathrm{em}$ água, usando-se $10 \mathrm{ml}$ da solução para hidrólise da sacarose e $3 \mathrm{ml}$ para desproteinização. O doseamento foi monitorado a partir de $0,2 \mathrm{ml}$ ou $0,3 \mathrm{ml}$ do extrato desproteinizado no caso dos açúcares redutores e $1 \mathrm{ml}$ da solução após hidrólise da sacarose desproteinizada. Os resultados foram expressos em gramas de glicose por $100 \mathrm{ml}$ de suco.

Vitamina C total: Em parte do suco acrescentou-se ácido oxálico $(80 \mathrm{ml}) \mathrm{e}$ kiesselgur (seguido de filtração). A mistura foi mantida a $-18^{\circ} \mathrm{C}$ por até no máximo 24 horas para avaliação do teor de vitamina C. Tomou-se $20 \mathrm{ml}$ do extrato e adicionou-se $80 \mathrm{ml}$ de ácido oxálico $(0,5 \%)$ e para o doseamento utilizou-se $1 \mathrm{ml}$ do filtrado para $3 \mathrm{ml}$ da solução de ácido oxálico $0,5 \%$. O ácido ascórbico (após oxidação a ácido dehidroascórbico) foi doseado pelo método colorimétrico com o 2,4-dinitrofenilhidrazina, segundo Strohecker \& Henning (1967). Os resultados foram expressos em $\mathrm{mg}$ por $100 \mathrm{ml}$ de suco.

Clorofila total: Foi determinada na casca, previamente congelada em nitrogênio líquido, (espessura de aproximadamente $1 \mathrm{~mm})$. Utilizou-se para desin- tegração, homogeneizador de tecidos, conforme metodologia de Bruinsma (1963), $1 \mathrm{~g}$ do material para $10 \mathrm{ml} \mathrm{de}$ água destilada. Ao volume do extrato, após a homogeneização, adicionou-se acetona p.a. até a completa descoloração, seguido de filtração. $\mathrm{O}$ volume final do extrato foi de $50 \mathrm{ml}$. A leitura da absorbância foi efetuada a $652 \mathrm{~nm}$. Os níveis de clorofila total foram determinados em mg/100g de casca, segundo a equação adotada por Engel \& Poggiani (1991):

clorofila total $=\left[\left(\mathrm{A}_{652} \times 1000 \mathrm{x} \mathrm{v} /\right.\right.$ $1000 \mathrm{w}) / 34,5]^{\prime} 100$

onde: $\mathrm{v}=$ volume final do extrato clorofila-acetona; $\mathrm{w}=$ peso da casca $\mathrm{em}$ $\mathrm{g} ; \mathrm{A}_{625}=$ leitura da absorbância a $652 \mathrm{~nm}$.

Análise estatística: As análises de variância dos dados foram efetuadas utilizando-se o software SPSSPC (Norusis, 1990). A comparação entre os estádios de maturação foi realizada através do teste de Tukey ao nível de $5 \%$ de probabilidade (Gomes, 1987).

\section{RESULTADOS E DISCUSSÃO}

Firmeza da polpa, pectina total e pectina solúvel: Houve redução de $54 \%$ na firmeza da polpa dos frutos do estádio de maturação I até o $\mathrm{V}$, similar ao verificado por Lester \& Dunlap (1985) durante o desenvolvimento e amadurecimento de Cucumis melo L. var. reticulatus e por Bianco \& Pratt (1977) para o melão cantaloupe 'PMR 45' durante o amadurecimento.

$\mathrm{O}$ amolecimento dos frutos durante a maturação, característica comum, é atribuída à hidrólise de vários polissacarídeos estruturais, sendo as substâncias pécticas os principais. Entretanto, neste experimento não houve diferença significativa $(\mathrm{p}<0,05)$ entre os níveis de pectina solúvel durante a maturação.

Em geral, a degradação de polissacarídeos da parede celular é acompanhada por aumento na atividade de hidrolases tais como poligalacturonases (PG enzimas responsáveis pela solubilização de pectina), pectinametilesterases (PME - grupo de enzimas que catalisa a desesterificação de metilésteres galactosil uronatos da pectina a grupos carboxilas livres) e endo-b-(1-4) glucanases.

Lester \& Dunlap (1985) estudaram o processo de amolecimento de melão reticulatus e constataram que não houve mudança nos teores de pectina, hemicelulose e celulose. Estes pesquisadores não conseguiram explicar o mecanismo que controla o amolecimento do melão através de correlação com enzimas de degradação da parede celular. A atividade das duas principais enzimas (PG e PME) permaneceu constante ou declinou durante o período de desenvolvimento e senescência do fruto; entretanto, Gross \& Sams (1984) e McCollum et al. (1989) relataram diminuição no tamanho molecular das pectinas, perda de resíduos de galactosil e mudanças no tamanho molecular dos polímeros hemicelulósicos durante o amadurecimento do melão. A ligação cruzada dos polímeros pécticos mediada pelo cálcio tem sido citada como um mecanismo controlador do amolecimento em maçã (Willey, 1977) e em tomate (Poovaiah \& Nukaya, 1979). Entretanto, a concentração deste elemento parece não estar associada com a firmeza do melão (Lester \& Dunlap, 1985). Apesar das tentativas de elucidar o mecanismo envolvido no amolecimento do melão (Lester, 1988; Lester, 1990), pouco se sabe acerca da atuação de enzimas diretamente relacionadas com o processo.

pH e acidez total titulável: $O$ estádio de maturação I apresentou o menor valor de $\mathrm{pH}(5,70)$, concordante com a concentração mais elevada de acidez total titulável (13mg de ácido cítrico anidro/100ml de suco). A variação nos níveis de acidez total titulável na maturação do melão possui pouco significado prático em função da baixa concentração.

Sólidos solúveis e açúcares: $\mathrm{O}$ teor mais baixo de SS $(6,99 \%)$ foi registrado no estádio de maturação I, diferindo significativamente dos demais tratamentos, porém, os conteúdos mais baixos de açúcares totais foram observados nos estádios I e II.

Pratt et al. (1977) também observaram aumento no teor de SS em frutos de melão colhidos em diferentes estádios de maturação. Oggle \& Christopher (1957) observaram um aumento no conteúdo de SS entre os estádios de maturação fullslip e half-slip de diferentes cultivares de melão cantaloupe. Portanto, deve-se estar atento para o ponto ideal de colheita dos frutos. 
O teor de açúcares totais correspondeu, em média, a $64 \%$ do conteúdo de SS, sendo o estádio de maturação III o que apresentou maior proporção (74\%). Artés et al. (1993) verificaram proporções variando de $57 \%$ (cv. Piel de Sapo) até $86 \%$ (cv. Galia); enquanto que Cohen \& Hicks (1986) encontraram valores de 57, 52 e $59 \%$, respectivamente, para as cvs. Gold Star, Saticoy e Superstar.

$\mathrm{O}$ aumento no conteúdo de SS durante a maturação do melão pode ser atribuído a síntese de estaquiose nas folhas e o conseqüente transporte para o fruto, onde é convertido em sacarose (Hughes \& Yamaguchi, 1983). Presume-se que o fruto possua um sistema de enzimas capaz de metabolizar este oligossacarídeo. Gross \& Pharr (1982) mostraram que um extrato do pedúnculo do fruto foi capaz de converter in vitro galactose-1-fosfato e frutose a sacarose, evidentemente, via UDP-galactosepirofosforilase (EC 2.7.7.10), UDPgalactose-4-epimerase (EC 5.1.3.2.) e sacarose sintase (EC 1.4.1.13). Isto também implicaria que b-galactosidase (EC 3.2.1.23) e galactoquinase (EC 2.7.1.6) participam da reação completando a conversão de estaquiose a sacarose (Knee et al., 1991).

Considerando textura e SS concluiuse que o estádio de maturação II é o mais indicado para a colheita do melão tipo Galia, híbrido Nun 1380, nas condições de cultivo deste experimento. Neste estádio de maturação o fruto apresentou o teor mínimo de SS exigido pelo mercado importador (SS superior a $9 \%$ ) e resistência mecânica ao manuseio póscolheita (firmeza da polpa superior a $50 \mathrm{~N}$ ). Além disso, nos estádios de maturação mais avançados não se registrou elevação no teor de SS. Entretanto, como o estádio de maturação III apresentou o teor mais elevado de açúcares totais, pode também ser utilizado como ponto de colheita, principalmente, quando o fruto for destinado a mercados mais próximos.

O estádio de maturação I apresentou o teor de açúcares redutores mais elevado $(2,92 \%)$ e o estádio V mais baixo $(1,67 \%)$. A redução no teor de açúcares redutores foi concomitante à elevação na concentração de sacarose. No estádio de maturação inicial os açúcares redutores corresponderam a, aproximadamente, $70 \%$ dos açúcares totais, enquanto que no último estádio de maturação este correspondeu, aproximadamente, a apenas $26 \%$.

Bianco \& Pratt (1977) também verificaram aumento na concentração de sacarose e redução no teor de açúcares redutores durante o amadurecimento de melão cantaloupe 'PMR 45'.

A sacarose é o principal açúcar livre encontrado no melão maduro (Hughes \& Yamaguchi, 1983; Lingle et al. 1987; McCollum et al., 1988) e o seu nível continua aumentando durante o desenvolvimento do fruto, enquanto que os níveis de glicose e frutose permanecem inalterados ou diminuem. Estes pesquisadores verificaram que o aumento na concentração de sacarose está correlacionado com o declínio na atividade da invertase ácida (EC 3.2.1.26), a qual apresenta níveis de atividade muito baixos no fruto maduro.

Ranwala \& Masuda (1991) reportaram acúmulo de sacarose durante o desenvolvimento de Cucumis melo L. cv Prince. Este acúmulo também foi correlacionado com diminuição na atividade das invertases (Ranwala et al., 1991).

Vitamina C total: Houve diferença significativa no teor de vitamina $\mathrm{C}$ total entre os estádios de maturação. $\mathrm{O}$ melão colhido no estádio de maturação I apresentou o menor teor de vitamina $\mathrm{C}$ total $\left(20,63 \mathrm{mg}(100 \mathrm{ml})^{-1}\right.$ de suco). O estádio de maturação $\mathrm{V}$ apresentou $\mathrm{o}$ teor mais elevado $\left(32,23 \mathrm{mg}(100 \mathrm{ml})^{-1}\right.$ de suco). Não houve variação entre os estádios de maturação II, III e IV.

$\mathrm{O}$ aumento da concentração de vitamina $\mathrm{C}$ total durante a maturação foi acompanhado por aumento no conteúdo de açúcares totais. Os valores de vitamina $\mathrm{C}$ total encontrados neste ensaio para os estádios de maturação II até $\mathrm{V}$ são bastante semelhantes aqueles reportados por Dhiman et al. (1995) para diferentes genótipos de melão. Esses autores verificaram concentrações médias de 32,$49 ; 27,73 ; 28,50$ e $24,90 \mathrm{mg}$ $(100 \mathrm{ml})^{-1}$ de suco, respectivamente, para os genótipos MR-12, Hara Madhu, Punjab Sunehri e Punjab.

Clorofila total: $\mathrm{O}$ estádio de maturação I apresentou o teor médio mais elevado de clorofila total $(50,00 \mathrm{mg} /$ $100 \mathrm{~g}$ de casca) enquanto que o estádio de maturação $\mathrm{V}$ apresentou o menor $(23,91 \mathrm{mg} / 100 \mathrm{~g}$ de casca). Isto representa uma redução de 52,2\% no conteúdo de clorofila total na casca do fruto entre os estádios de maturação I e V.

Apesar da redução no teor de clorofila total, o fruto ainda apresentou-se esverdeado no estádio de maturação V, o que dificulta a comercialização, pois as principais cultivares de melão tipo Galia existentes no mercado apresentam frutos amarelos quando maduros.

Os valores médios para os teores de clorofila total são comparáveis aqueles obtidos por Flügel \& Gross (1982) apenas para o último estádio de maturação. Nos demais estádios os valores são bastante superiores. Isto reforça a discussão que o híbrido avaliado apresenta teores elevados de clorofila total quando comparado com outras cultivares de melão 'Galia'. Esta informação é extremamente importante para os programas de melhoramento do melão 'Galia', pois a cor do fruto é uma importante característica de qualidade considerada pelo consumidor.

\section{LITERATURA CITADA}

ARTÉS, F.; ESCRICHE, A.J.; MARTINEZ, J.A.; MARIN, J.G. Quality factors in four varieties of melons (Cucumis melo, L.). Journal of Food Quality, v. 16, n. 2, p. 91-100, 1993.

AULENBACH, B.B.; WORTINGTON, J.T. Sensory evalution of muskmelon: is soluble solids content a good quality index. HortScience, v. 9, n. 2, p. 136 - 137, 1974.

BIANCO, V.V.; PRATT, H.K. Composition changes in muskmelon during development and in response to ethylene treatment. Journal of the American Society for Horticultural Science, v. 102, n. 2, p. 127 133, 1977.

BLUMENKRANTZ, N.; ASBOE-HANSEN, G. New method for quantitative determination of uronic acids. Analitical Biochemistry, v. 54, p. 484 - 489, 1973.

BOSLAND, J.M.; HUGHES, D.L.; YAMAGUCHI, M. Effects of glyphosine and triacontanol on growth, yield, and soluble solids content of 'PMR 45' muskmelons. HortScience, v. 14, n. 6, p. 729 - 730, 1979.

BRUINSMA, J. The quantitative analysis of chlorophylls A and B in plant extracts. Photochemistry and Photobiology, v. 2, p. 241 - 249, 1963.

COHEN, R.A.; HICKS, J.R. Effect of storage on quality and sugars in muskmelon. Journal of American Society for Horticultural Science, v. 111, n. 4, p. 553 - 557, 1986. 
DHIMAN, J.S.; TARSEM L.A.L.; BAJAJ, K.L. Evaluation of muskmelon (Cucumis melo L.) genotypes for multiple disease resistance, yield, and quality characteristics. Tropical Agricultural, v. 72, n. 1, p. 58 - 62, 1995.

ENGEL, V.L.; POGGIANI, F. Estudo da concentração de clorofila nas folhas e seu espectro de absorção de luz em função do sombreamento em mudas de quatro espécies florestais. Revista Brasileira de Fisiologia Vegetal, Londrina, v. 3, n. 1, p. 39 - 45, 1991.

FADY, C. Critères objectifs de la qualité gustative des fruits: utilisation commerciale de ces critéres. Fruits, v. 38, n. 7 - 8, p. 547 - 551, 1983.

FLÜGEL, M.; GROSS, J. Farbstoff-und plastidenveränderungen während der fruchtreife bei zuckermelonen, Cucumis melo cv. Galia. Angew Botanik, v. 56, p. 393 - 406, 1982

GOMES, P.F. Curso de Estatitisca Experimental. São Paulo: Nobel, 1987.

GROSS, K.C.; PHARR, D.M. A potential pathway for galactose metabolism in Cucumis sativus L., A stachyose transporting species. Plant Physiology, v. 69, p. 117 - 121, 1982.

GROSS, K.C.; SAMS, C.E. Changes in cell wall neutral sugar composition during fruit ripening: a species survey. Phytochemistry, Elmsford, v. 23, n. 11, p. 2457 - 2461, 1984

HUGHES, D.L.; YAMAGUCHI, M.I Identification and distribution of some carbohydrates in the muskmelon plant, HortScience, v. 18, n. 5, p. 739 - 740, 1983

KINTNER III, P.K.; VAN BUREN, J.P. Carbohydrate interference and its correction in pectin analysis using the $\mathrm{m}$ hydroxydiphenyl method. Journal of Food Science, v. 47, p. 756 - 764, 1982.

KNEE, M; PAULL, R.E.; ARIE, R.B.; HAWKER, J.S. Enzymes in fruits. In: FOX, P.F. Food Enzymology, New York: Ensevier Applied Science, 1991. p. 545 - 598.

KRAMER, A. Fruits and Vegetables. In: __ e TWIGG, B.A. Quality Control for the Food Industry. Connecticut: Avi Publishing Company, 1973. v. 2, p. 157 - 227.

LESTER, G.E. Comparisons of 'Honey Dew' and netted muskmelon fruit tissues in relation to storage life. HortScience, v. 23, n. 1, p. 180 182,1988
LESTER, G.E. Lipoxigenase activity of hipodermal- and middle- mesocarp tissues from netted muskmelon fruit during maturation and storage. Journal of the American Society for Horticultural Science, v. 115, p. 612 - 615, 1990.

LESTER, G.E.;DUNLAP, J.R. Physiological changes during development and ripening of 'Perlita' muskmelon fruits. Scientia Horticultural, v. 26, p. 323 - 331, 1985.

LESTER, G.E.; STEIN, E. Plasma membrane physicochemical changes during maturation and postharvest storage of muskmelon fruit. Journal of the American Society for Horticultural Science, v. 118, n. 2, p. 223 227, 1993.

LINGLE, S.E.; LESTER, G.E.; DUNLAP, J.R Effect of postharvest heat treatment and storage on sugar metabolism in polyethylenewrapped muskmelon fruit. HortScience, v. 22, n. 5, p. 917 - 919, 1987.

McCOLLUM, T.G.; HUBER, D.J.; CANTLIFFE, D.J. Modification of polyuronides and hemicelluloses during muskmelon fruit softening. Physiologia Plantarum, v. 76, p. 303 -309, 1989.

McCOLLUM, T.G. ; HUBER, D.J.; CANTLIFFE, D.J. Soluble sugar accumulation and activity of related enzimes during muskmelon fruit development. Journal of the American Society for Horticultural Science, v. 113, n. 3, p. 399 - 403, 1988.

McCREADY, P.M.; McCOOMB, E.A. Extraction and determination of total pectin materials. Analytical Chemistry, v. 24, n. 12, p. 1586 1888, 1952.

NORUSIS, M.J. SPSS statistics. Illinois, SPSS Inc., 1990.

ODET, J. Le melon. Paris: Ctifl, 1993, 295 p.

OGGLE, W.L.; CHRISTOPHER, E.P. The influence of maturity, temperature and duration of storage on quality of cantaloupes. Proceeding American Society Horticultural Science, New York, v. 70, p. 319 - 324, 1957.

POOVAIAH, B.W.; NUKAYA, A Polygalacturonase and cellulase enzymes in the rutgers and mutant rin tomato fruits and their relatioship to the respiratory climateric. Plant Physiology, v. 64, p. 534 - 537, 1979.
PRATT, H.K. ; GOESCHL, J.D.; MARTIN, F.W. Fruit growth and development, ripening, and the role of ethylene in the 'Honey Dew' muskmelon. Journal of the American Society for Horticultural Science, v. 102, n. 2, p. 203 - 210, 1977.

PROTRADE. Melones - Export Manual: Tropical fruits and vegetables. Eschborn, GTZ, 1995. $36 \mathrm{p}$.

RANWALA, A.P.; IWANAMI, S.; MASUDA, H. Acid and neutral invertase in the mesocarp of developing muskmelon (Cucumis melo L. cv. Prince) fruit. Plant Physiology, v. 96, p. 881 - 886, 1991.

RANWALA, A.P.; MASUDA, H. Purification of soluble acid invertase from the mesocarp of developing muskmelon (Cucumis melo L. cv. Prince) fruit. Agriculture Biological Chemistry, v. 55, n. 9, p. 2435 - 2436, 1991.

SCOTT, G.W.; MacGILLIVRAY, H.H. Variation in solids of the juice from different regions in melon fruits. Hilgardia, v. 13, n. 2, p. 69 79, 1940.

SOUTHGATE, D.A.T. Determination of foods carbohydrates, London: Elservier Applied Science, 1991, $232 \mathrm{p}$.

SOUZA, M.C.; MENEZES, J.B.; ALVES, R.E. Tecnologia pós-colheita e produção de melão no Estado do Rio Grande do Norte, Horticultura Brasileira, Brasília, v. 12, n. 2, p. 188 - 190, 1994.

STROHECKER, R.L.; HENNING, H.M. Analisis de vitaminas: metodos comprobados. Madrid: Paz Montalvo, 1967, 428 p.

VAULX, R.D.; AUBERT, S. Évolution comparée des fruits de deux cultivars de Melon "Doublon" et "Védrantais" (type "Charentais") au cours des derniers jours de la maturation. Annuaire Technologie Agriculture, v. 27, n. 3, p. 227 - 241, 1977.

WILLEY, R.C. Uses of enzymes in fruit and vegetable processing. In: Ory, R.L.; ANGELO, A.J.St. Enzymes in food and beverage processing, Washington: ACS, 1977, p.198 $-208$.

ZAPATA, N.M. ; CABRERA, P.; BANÕN, S.; ROTH, P. El melon, Madrid: Mundi-Prensa, 1989, 173 p. 